\title{
Time to recovery after general anesthesia at hospitals with and without a phase I post-anesthesia care unit: a historical cohort study
}

\section{Délai de récupération après une anesthésie générale dans les hôpitaux disposant d'une unité de soins postanesthésiques de phase I par rapport à des hôpitaux n'en disposant pas : une étude de cohorte historique}

\author{
Kokila N. Thenuwara, MD, MBBS, MME, MHCDS - Tatsuya Yoshimura, MD, MBA • \\ Yoshinori Nakata, MD, MBA • Franklin Dexter, MD, PhD, FASA $\mathbb{D}$
}

Received: 9 April 2018/Revised: 30 May 2018/Accepted: 31 May 2018/Published online: 12 September 2018

(C) Canadian Anesthesiologists' Society 2018

\begin{abstract}
Purpose There is little knowledge about how hospitals can best handle disruptions that reduce post-anesthesia care unit (PACU) capacity. Few hospitals in Japan have any $P A C U$ beds and instead have the anesthesiologists recover their patients in the operating room. We compared postoperative recovery times between a hospital with (University of Iowa) and without (Shin-yurigaoka General Hospital) a PACU.

Methods This historical cohort study included 16 successive patients undergoing laparoscopic gynecologic surgery with endotracheal intubation for general anesthesia, at each of the hospitals, and with the hours from OR entrance until the last surgical dressing applied
\end{abstract}

Drs. Thenuwara and Yoshimura contributed equally to this research.

K. N. Thenuwara, MD, MBBS, MME, MHCDS

Department of Anesthesia, University of Iowa, Iowa City, IA, USA

T. Yoshimura, MD, MBA

Department of Anesthesia, Shin-yurigaoka General Hospital,

Kawasaki, Kanagawa, Japan

Y. Nakata, MD, MBA

Teikyo University, Tokyo, Japan

F. Dexter, MD, PhD, FASA ( $\square)$

Division of Management Consulting, Department of Anesthesia,

University of Iowa, 200 Hawkins Drive, 6-JCP, Iowa City, IA

52242, USA

e-mail: Franklin-Dexter@UIowa.edu

URL: https://www.FranklinDexter.net $\geq$ two hours. Postoperative recovery times, defined as the end of surgery until leaving for the surgical ward, were compared between the hospitals.

Results The median [interquartile range] of recovery times was 112 [94-140] min at the University of Iowa and 22 [18-29] $\min$ at the Shin-yurigaoka General Hospital. Every studied patient at the University of Iowa had a longer recovery time than every such patient at Shinyurigaoka General Hospital (Wilcoxon-Mann-Whitney, $P$ $<0.001)$. The ratio of the mean recovery times was 4.90 (95\% confidence interval [CI], 4.05 to 5.91; $P<0.001)$ and remained comparable after controlling for surgical duration (5.33; 95\% CI, 3.66 to 7.76; $P<0.001)$. The anesthetics used in the Iowa hospital were a volatile agent, hydromorphone, ketorolac, and neostigmine compared with the Japanese hospital where bispectral index monitoring and target-controlled infusions of propofol, remifentanil, acetaminophen, and sugammadex were used. Conclusions This knowledge can be generally applied in situations at hospitals with regular PACU use when there are such large disruptions to PACU capacity that it is known before a case begins that the anesthesiologist likely will need to recover the patient (i.e., when there will not be an available PACU bed and/or nurse). The Japanese anesthesiologists have no PACU labour costs but likely greater anesthesia drug/monitor costs.

Résumé

Objectif Nous savons peu de choses sur la façon dont les hôpitaux peuvent le mieux résoudre les perturbations qui 
réduisent la capacité des unités de soins postanesthésie (salle de réveil). Au Japon, peu d'hopitaux disposent de lits de salle de réveil et les anesthésiologistes laissent les patients récupérer dans la salle d'opération. Nous avons comparé le délai de récupération postopératoire entre un hôpital disposant d'une salle de réveil (Université de l'Iowa) et un hôpital n'en ayant pas (Hôpital général Shinyurigaoka).

Méthodes Cette cohorte historique a inclus 16 patientes successives subissant une chirurgie gynécologique par voie laparoscopique avec intubation endotrachéale et anesthésie générale dans chacun des hôpitaux lorsque le délai entre l'entrée au bloc opératoire et le dernier pansement chirurgical mis était $\geq 2$ heures. Le temps de récupération postopératoire, défini comme étant le délai écoulé entre la fin de l'intervention et le départ pour l'unité de chirurgie a été comparé entre les 2 hôpitaux.

Résultats La valeur médiane [plage interquartile] $d u$ temps de récupération a été de 112 [94-140] minutes à l'université de l'Iowa et de 22 [18-29] minutes à l'hôpital général Shin-yurigaoka. Toutes les patientes étudiées à l'université de l'Iowa ont eu un temps de récupération plus long que chacune des patientes de l'hôpital général Shinyurigaoka (test de Wilcoxon-Mann-Whitney, $P<0$,001). Le rapport des temps moyens de récupération a été de 4,90 (intervalle de confiance [IC] à $95 \%: 4,05$ à 5,91; $P<$ $0,001)$ et est resté comparable après contrôle pour la durée de l'intervention (5,33; IC à 95\%, 3,66 à 7,76; $P<0,001)$. Les agents anesthésiques utilisés à l'hôpital de l'Iowa étaient un agent volatil, l'hydromorphone, le kétorolac et la néostigmine alors que dans l'hôpital japonais le monitorage de l'indice bispectral et des perfusions contrôlées avec cible de propofol et de rémifentanil, de l'acétaminophène et du sugammadex ont été utilisés.

Conclusions Ces connaissances peuvent être appliquées plus généralement aux hôpitaux disposant de salles de réveil quand on sait à l'avance que l'anesthésiologiste aura probablement besoin de laisser récupérer le patient en salle d'opération à cause de perturbations importantes des capacités de la salle de réveil (c'est-à-dire, absence de lit et/ou d'infirmière disponible). Les anesthésiologistes japonais n'engendrent pas de frais de personnel en salle de réveil, mais occasionnent probablement des frais plus élevés de monitorage et de médicaments anesthésiques.

Sento et al. recently published their survey of hospitals in Japan finding that only $16 \%$ have any phase I postanesthesia care unit (PACU) beds. ${ }^{1}$ The phase I discharge-to-ward PACU is differentiated from the discharge-to-home phase II PACU of outpatient surgical departments., ${ }^{2, \mathrm{~A}}$ In Japan, patients are recovered in the operating room (OR) by the anesthesiologist and then go directly to the hospital ward. This occurs despite Japanese hospitals often having a higher postoperative patient-tonurse ratio than in the USA (i.e., it is not because the Japanese wards are functioning like PACUs). ${ }^{\text {B }}$ Potentially, in Japan, more expensive devices and drugs are being used, facilitating fast recovery in the OR, while in the USA expensive PACU nurse labour is being used instead. We therefore speculate that there may be useful insights from the anesthesia techniques used in Japanese hospitals that recover patients exclusively in their ORs. Anesthesiologists working at hospitals with regular PACUs can use the insights when expected to recover the patient (i.e., the PACU is anticipated to be full).

In this historical cohort study, we compared the surgical recovery times between the University of Iowa hospital in Iowa City and the Shin-yurigaoka General Hospital near Tokyo. Our objective was to test the hypothesis that the times from end of surgery until the patients left for the surgical ward (i.e., "recovery times") would be much longer at the University of Iowa with a PACU compared with a Tokyo hospital that does not use a PACU.

\section{Methods}

The Institutional Review Boards (IRB) of the University of Iowa (201801768; 25 January 2018) and of Shin-yurigaoka General Hospital (20180219-1; 20 February 2018) approved this historical cohort study and considered it exempt from the requirement of obtaining written consent of patients.

The population studied was patients undergoing laparoscopic gynecologic surgery. We chose this population because it was the one category with many patients at both the investigators' hospitals. No restriction was placed on whether the patient leaving the PACU (University of Iowa) or OR (Shin-yurigaoka General Hospital) was going to a hospital ward or to a phase II PACU location (see footnote $\mathrm{A}$ in the introduction). All successive patients were studied that met the following inclusion criteria: i) a laparoscopic gynecologic procedure was scheduled and performed for at least part of the

\footnotetext{
${ }^{\mathrm{A}}$ For the current paper, we consider patients discharged to ward. Generally, patients may be discharged from the phase I postanesthesia care unit (PACU) to the phase II PACU, a ward, or intensive care unit.

B As reported by the Chief gynecologic nurse, each ward nurse at Shin-yurigaoka General Hospital cares for an average of seven gynecologic patients, more than the five or six at the University of Iowa.
} 
surgical case (i.e., it could have been completed with laparotomy); ii) endotracheal intubation for general anesthesia was done; iii) actual hours from OR entrance until the last surgical dressing was placed on the patient was $\geq$ two hours.

Patients were selected in reverse sequence from 31 December 2017. Electronic chart review was performed for 16 successive patients (see the power analysis below). The requirement was placed on the protocol design that the study would be reevaluated if 16 such patients were not identified who had undergone surgery within six months (i.e., all patients studied had surgery between 1 July 2017 and 31 December 2017). The dates were otherwise not recorded; only times were recorded, in accordance with the IRB protocol. This was because as the specific hospitals were being identified, the combination of procedure (inherently specifying sex) and date potentially could lead to identification of the patients. ${ }^{3,4}$

The primary endpoint of this study was the "recovery time," defined as the time from end of surgery (i.e., final wound covered $)^{5}$ until the patient left for the hospital ward. If there were differences in recovery times, the anesthetic monitors and drugs used would be of interest and were therefore also recorded.

\section{Statistical methods}

The primary method of statistical analysis was chosen $a$ priori. The Wilcoxon-Mann-Whitney test was used to estimate the probability $\left(p^{\prime \prime}\right)$ that a randomly selected case at the University of Iowa had a longer time to recovery than did a randomly selected case at the Shin-yurigaoka General Hospital.

The secondary methods of analysis used generalized linear modeling, a log link function, and heteroscedasticrobust standard error. This analysis was performed while controlling for covariates, including the time from OR entrance to end of surgery. We expected this variable to be a significant covariate that could cause bias because of its positive correlation among all types of procedures with the time from end of surgery to extubation. ${ }^{6}$

The following power analysis, as reported to the IRBs, was used to determine the sample size. Because of the multiple planned analyses, a type I two-sided error rate (alpha) of 0.01 was used: $\mathrm{Z}_{\text {alpha/2 }}=\mathrm{Z}_{0.005}=2.58$. In addition, a $90 \%$ statistical power to detect a difference between hospitals was planned: $\mathrm{Z}_{\text {beta }}=\mathrm{Z}_{0.10}=1.28$. Assuming equal sample sizes at each of the two hospitals, equation A3.2 in Divine et al. was applied to our problem ${ }^{7}$; accordingly, each group's $N=2.48 /\left(p^{\prime \prime}-0.5\right)^{2}$. From preliminary discussions about respective patients' typical recovery times, we expected no overlap of recovery time between the US and Japanese hospitals, but also recognized that there may be some overlap due to uncommon patient or operational conditions. We used $p^{\prime \prime}=0.90$ (i.e., at most $10 \%$ overlap between groups) and thus obtained data on 16 consecutive patients meeting the inclusion criteria at each hospital.

\section{Results}

All 16 of the patients at the Shin-yurigaoka General Hospital Tokyo went to the hospital ward directly from the OR. None of the 16 University of Iowa patients needed to wait in the PACU because a ward bed was unavailable (i.e., none of the measured recovery times was prolonged for such non-clinical reasons). All the data elements recorded about each patient are listed in Table 1 along with the summary measures.

The median [interquartile range] of recovery times was 112 [94-140] min at the University of Iowa and 22 [18-29] min at the Shin-yurigaoka General Hospital (Figure). Every studied patient at the University of Iowa had a longer recovery time than every such patient at Shin-yurigaoka General Hospital (Wilcoxon-Mann-Whitney, $P<0.001$ ) (Figure). The ratio of the mean recovery times was 4.90 (95\% confidence interval $[\mathrm{CI}], 4.05$ to $5.91 ; P<0.001$ ), which remained comparable while controlling for the duration of surgery $(5.33 ; 95 \% \mathrm{CI}, 3.66$ to $7.76 ; P<$ $0.001)$. Thus, the estimated mean recovery time at Shinyurigaoka General Hospital was approximately $80 \%$ [i.e., 1 $-(1 / 4.90)=79.6 \%$ and $1-(1 / 5.33)=81.2 \%]$ faster than that of the University of Iowa Hospital.

Covariates that could not be studied were those that differed uniformly between the hospitals (Table 1). None of the patients at the University of Iowa had BIS ${ }^{\mathrm{TM}}$ (Medtronic; Minneapolis, MN, USA) monitoring $v s$ all the patients at Shin-yurigaoka General Hospital. In addition, all the patients at the University of Iowa had anesthetic maintenance with a volatile agent, whereas all the patients at Shin-yurigaoka General Hospital received targetcontrolled infusions of propofol. Analgesics, in addition to fentanyl, were hydromorphone and/or ketorolac at the University of Iowa compared with remifentanil and acetaminophen at Shin-yurigaoka General Hospital. Reversal of neuromuscular blockade was done with neostigmine at the University of Iowa $v s$ sugammadex at Shin-yurigaoka General Hospital.

\section{Discussion}

At a Japanese hospital with no PACU, where anesthesiologists recover their patients in the OR, mean recovery times after general anesthesia for laparoscopic 
Table 1 Comparisons of patients and anesthetics at University of Iowa and Shin-yurigaoka General Hospital in Tokyo

\begin{tabular}{|c|c|c|c|}
\hline Variable & University of Iowa & $\begin{array}{l}\text { Shin-yurigaoka General Hospital } \\
\text { (Tokyo) }\end{array}$ & $P$ value \\
\hline BIS monitor & $\begin{array}{l}\text { Used } 0 \\
\text { Not used } 16\end{array}$ & $\begin{array}{l}\text { Used } 16 \\
\text { Not used } 0\end{array}$ & $<0.001$ \\
\hline Maintenance hypnotic & $\begin{array}{l}\text { Propofol target- controlled infusion } \\
\quad 0 \\
\text { Sevoflurane } 9 \\
\text { Isoflurane } 6 \\
\text { Desflurane } 1\end{array}$ & $\begin{array}{l}\text { Propofol target-controlled infusion } 16 \\
\text { Sevoflurane } 0 \\
\text { Isoflurane } 0 \\
\text { Desflurane } 0\end{array}$ & $<0.001$ \\
\hline Additional analgesics & $\begin{array}{l}\text { Remifentanil and acetaminophen } 0 \\
\text { Hydromorphone and ketorolac } 7 \\
\text { Hydromorphone } 7 \\
\text { Ketorolac } 2 \\
\text { None } 0\end{array}$ & $\begin{array}{l}\text { Remifentanil and acetaminophen } 15 \\
\text { Hydromorphone and ketorolac } 0 \\
\text { Hydromorphone } 0 \\
\text { Ketorolac } 0 \\
\text { None } 1\end{array}$ & $<0.001$ \\
\hline Reversal of neuromuscular blockade & $\begin{array}{l}\text { Sugammadex } 0 \\
\text { Neostigmine } 14 \\
\text { None } 2\end{array}$ & $\begin{array}{l}\text { Sugammadex } 15 \\
\text { Neostigmine } 1 \\
\text { None } 0\end{array}$ & $<0.001$ \\
\hline Time from OR entrance to end of surgery (hr) & $\begin{array}{l}\text { Median } 4.72 \\
\text { 25th percentile } 4.02 \\
75 \text { th percentile } 5.51 \\
\text { Mean } 4.91\end{array}$ & $\begin{array}{l}\text { Median } 2.70 \\
\text { 25th percentile } 2.39 \\
\text { 75th percentile } 3.41 \\
\text { Mean } 2.99\end{array}$ & 0.001 \\
\hline Procedure & $\begin{array}{l}\text { Hysterectomy } 13 \\
\text { Myomectomy } 1 \\
\text { Cystectomy } 0 \\
\text { Sacral colpopexy } 2\end{array}$ & $\begin{array}{l}\text { Hysterectomy } 7 \\
\text { Myomectomy } 6 \\
\text { Cystectomy } 3 \\
\text { Sacral colpopexy } 0\end{array}$ & 0.011 \\
\hline Decade of age (years) & $\begin{array}{l}\text { Median } 45 \\
25 \text { th percentile } 40 \\
75 \text { th percentile } 55\end{array}$ & $\begin{array}{l}\text { Median } 40 \\
\text { 25th percentile } 30 \\
75 \text { th percentile } 45\end{array}$ & 0.35 \\
\hline Time from end of surgery to tracheal extubation (min) & $\begin{array}{l}\text { Median } 11.0 \\
\text { 25th percentile } 7.5 \\
\text { 75th percentile } 19.5 \\
\text { Mean } 13.9\end{array}$ & $\begin{array}{l}\text { Median } 9.0 \\
\text { 25th percentile } 6.5 \\
\text { 75th percentile } 11.0 \\
\text { Mean } 8.9\end{array}$ & 0.36 \\
\hline ASA physical status & $\begin{array}{l}1-213 \\
33\end{array}$ & $\begin{array}{l}1-216 \\
30\end{array}$ & 0.23 \\
\hline Fentanyl before tracheal extubation & $\begin{array}{l}\text { Used } 14 \\
\text { Not used } 2\end{array}$ & $\begin{array}{l}\text { Used } 16 \\
\text { Not used } 0\end{array}$ & 0.48 \\
\hline Time of day of end of surgery & $\begin{array}{l}\text { Median 3:05 PM } \\
\text { 25th percentile 12:22 PM } \\
\text { 75th percentile 5:16 PM }\end{array}$ & $\begin{array}{l}\text { Median 3:52 PM } \\
\text { 25th percentile 1:38 PM } \\
\text { 75th percentile 4:44 PM }\end{array}$ & 0.55 \\
\hline $\begin{array}{l}\text { Another case performed in the OR after the current } \\
\text { case }\end{array}$ & $\begin{array}{l}\text { Yes } 10 \\
\text { No } 6\end{array}$ & $\begin{array}{l}\text { Yes } 9 \\
\text { No } 7\end{array}$ & 0.99 \\
\hline $\begin{array}{l}\text { Another case performed in the OR after the current } \\
\text { case and by the same surgeon }\end{array}$ & $\begin{array}{l}\text { Yes } 9 \\
\text { No } 7\end{array}$ & $\begin{array}{l}\text { Yes } 8 \\
\text { No } 8\end{array}$ & 0.99 \\
\hline Rocuronium & $\begin{array}{l}\text { Used } 16 \\
\text { Not used } 0\end{array}$ & $\begin{array}{l}\text { Used } 16 \\
\text { Not used } 0\end{array}$ & 1.00 \\
\hline Elective procedure & $\begin{array}{l}\text { Elective } 16 \\
\text { Urgent } 0\end{array}$ & $\begin{array}{l}\text { Elective } 16 \\
\text { Urgent } 0\end{array}$ & 1.00 \\
\hline
\end{tabular}

Categories were compared using Fisher's exact test. Continuous and ordered variables were compared using the Wilcoxon-Mann-Whitney test. $P$ values are two-sided. ASA $=$ American Society of Anesthesiologists; OR = operating room

At the University of Iowa, propofol was used for induction and not maintenance, and none of the analgesics was infused 


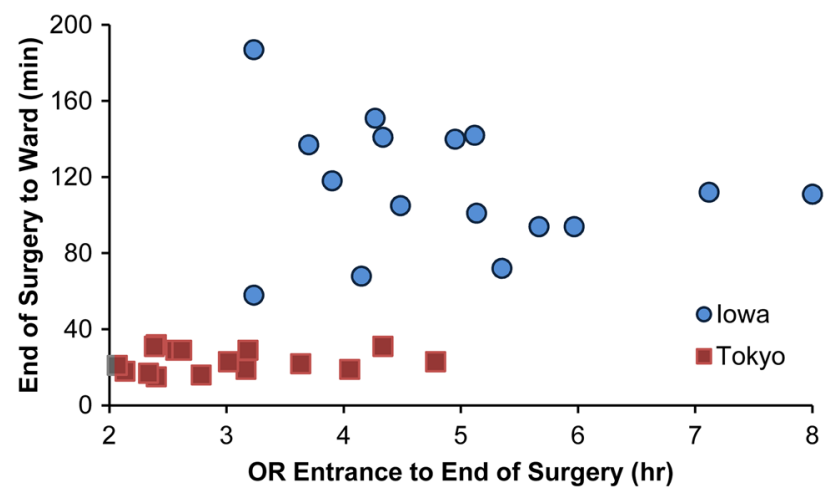

Figure Recovery time at the University of Iowa and at Shinyurigaoka General Hospital after general anesthesia for laparoscopic gynecologic surgery. The recovery time was the time from final wound covering until the patient left for the hospital ward. A potential independent variable that differed between hospitals was the time from operating room (OR) entrance to the final dressing on the patient (Tables 1 and 2)

gynecologic surgery were $80 \%$ faster than those of a US hospital that uses a PACU.

Our results have economic implications. An anesthetic with BIS monitoring, propofol target-controlled infusion, remifentanil, acetaminophen, and sugammadex will have a greater device and drug cost than one with sevoflurane, hydromorphone, ketorolac, and neostigmine. Nevertheless, if an anesthesiologist is going to recover the patient 1:1 rather than a nurse caring for two patients in a PACU ${ }^{2}$ (with anesthesiologist backup), the labour costs per hour will be greater. ${ }^{8,9}$ Thus, the Japanese anesthesiologists substitute more expensive supplies/drug costs for less of their time (i.e., labour costs). The approach of using the BIS monitor and drugs with fast recovery time is sustained, in part, by the Japanese' Diagnostic Procedure Combination hospital payment system that excludes anesthesia drugs, making them fee-for-service, paid by the patient's insurance; thus, the hospital lacks incentive for lesser cost. This approach not to reduce the time spent in the PACU but to facilitate its bypass altogether matches the findings of the pharmacoeconomics of anesthetic drugs and techniques for outpatient surgery. ${ }^{10-12}$ For outpatient surgery, this strategy lowers costs especially for facilities with many patients per day, an eight-hour ( $v s$ a longer tenhour) OR workday, and PACU nurses who either are salaried or work full-time hourly and frequently have overtime. $^{13,14}$

Our results are potentially useful at hospitals with regular PACU use when it is known before a case begins that the anesthesiologist likely will need to recover the patient in the OR (i.e., there will not be an available PACU bed and/or nurse). An example of such events is when there is damage to portions of the PACU (e.g., flooding). ${ }^{15}$ Other situations where this event might occur include when patients from another location (e.g., non-OR anesthetizing locations) are being recovered temporarily in the surgical PACU (e.g., the other location's PACU is temporarily closed for renovations). Nevertheless, our findings that different anesthetics can, in combination, result in recovery times that are only $20 \%$ as long were for gynecologic surgery (Table 2). Knowing before the case begins that the patient has a substantial chance of needing recovery in the OR generally would depend on there being PACU staffing shifts and start times chosen based on matching the expected peak number of PACU patients by time of day. ${ }^{16-20}$ Even then, when there is a large variability among days in the peak numbers of patients, predicting for the individual case is challenging. ${ }^{21}$ Nevertheless, this is not so when a disruption is so large that there will inevitably be cases every day with recovery in the OR. ${ }^{15}$ For example, if a 12-bed PACU only has eight beds available for surgical patients for a week (e.g., from renovation), and the other patients recover in the ORs, there will be negligible variability in the peak number of patients in the PACU (i.e., it will be eight patients for most of the workday). Planning can be done in this circumstance. ${ }^{22}$

\section{Study limitations}

We did not collect safety data and do not have the timing on when each patient met each of the multiple criteria for

Table 2 Ratio of mean recovery times between University of Iowa and Shin-yurigaoka General Hospital in Tokyo

\begin{tabular}{llll}
\hline $\begin{array}{l}\text { Variable from Table } 1 \text { that differs significantly but not completely } \\
\text { between hospitals }\end{array}$ & $\begin{array}{l}\text { Mean }(95 \% \text { confidence } \\
\text { interval) }\end{array}$ & $\begin{array}{l}P \text { value for ratio } \\
\text { of recovery times }\end{array}$ & $\begin{array}{l}P \text { value for } \\
\text { covariate }\end{array}$ \\
\hline None & $4.90(4.05$ to 5.91$)$ & $<0.001$ \\
Time from OR entrance to end of surgery & $5.33(3.66$ to 7.76$)$ & $<0.001$ & 0.49 \\
Hysterectomy & $4.92(4.11$ to 5.90$)$ & $<0.001$ & 0.91
\end{tabular}

Recovery time was measured as the period from end of surgery until the patient was ready to leave for the hospital ward. The non-significant effect of surgical time had a narrow confidence interval, with a 0.997 to 1.001 -fold longer recovery time for each additional one minute of surgical time (i.e., 0.9995 to 1.0000 per hour). The generalized linear modeling also was performed using the sequence of the patients at each hospital as a continuous variable: 4.89 (4.10 to 5.83), $P<0.0001$, and sequence $P=0.15$. OR $=$ operating room 
discharge to the ward. ${ }^{\mathrm{C}, 23}$ However, the hospital in Tokyo does not have a PACU for any of its patients (i.e., it was not just unavailable for the study patients); only $16 \%$ of hospitals in Japan have any PACU beds. ${ }^{1}$ Thus, the relevant issue is not whether patients can safely undergo surgery and then go directly to a hospital ward with no greater numbers of nurses there than in North America. The question is how long patients routinely wait in the ORs recovering. The answer is vastly less time (20\%) than that spent routinely in a phase I PACU. Nevertheless, while achieving this reduction in labour costs, the anesthetics were different and generally more expensive (i.e., substitution of drug/supply for labour costs). As referred to in the last paragraph of the results, from the data, we are unable to know which of the differences in drugs/supplies contribute to the briefer recovery times. We also cannot quantify whether recovery time is saved by not having a handoff of care or from heterogeneity in the use of discharge criteria. ${ }^{\mathrm{C}}$

We limited the procedure category to laparoscopic gynecologic surgery, though this was unlikely to have influenced our conclusions. The principal covariates for recovery time after general anesthesia are not surgical procedure or patient sex, but availability of anesthesiologists, transport personnel, or ward beds, as well as patient pain. ${ }^{24,25}$

We did not have a way to collect patients' initial postoperative pain scores, because the data were collected retrospectively. However, it is unlikely that differences in acute pain during the first couple of hours after surgery account for the 4.9-fold differences in recovery times. However, our conclusions are limited to the fact that the recovery times differ markedly between hospitals; we do not have a way to know how the differences were achieved.

The application of our study was in the consideration of using different anesthetic techniques to reduce recovery times when the PACU is full. An alternative strategy may be to revise case sequencing to reduce the peak necessary number of PACU nurses and beds. ${ }^{26}$ When there are sufficient nurses and beds to prevent delays from the OR into the PACU, case sequencing does not significantly reduce the necessary PACU nursing hours. ${ }^{27}$ Nevertheless, that may not be so under the conditions in the present study. This would not change the results of our study about

\footnotetext{
C At the University of Iowa, the postanesthesia care unit (PACU) discharge policy has three criteria in addition to those of the modified Aldrete score: $:^{23}$ normothermia, no indication of urinary retention or oliguria, and a minimum PACU time of $30 \mathrm{~min}$. The latter had no influence on results as every patient had a PACU time $>30 \mathrm{~min}$ (PACU minimum $36 \mathrm{~min}$ and recovery time minimum $58 \mathrm{~min}$ ). At Shin-yurigaoka General Hospital, discharge to the ward was left to the judgment of the anesthesiologist; the electronic anesthesia chart has a built-in checklist, which is the same as the modified Aldrete score. ${ }^{23}$
}

recovery times, but would reduce their usefulness, since if it were known ahead which patients likely will recovery in the ORs, the less expensive intervention would be case sequencing rather than using more expensive anesthetic drugs and supplies.

Conflicts of interest The Division of Management Consulting, Department of Anesthesia, University of Iowa, performs some of the calculations described in this article. Franklin Dexter receives no funds personally other than his salary and allowable expense reimbursements from the University of Iowa and has tenure with no incentive program. He and his family have no financial holdings in any company related to his work other than indirectly through mutual funds for retirement. Income from the Division's consulting work is used to fund Division research.

Editorial responsibility This submission was handled by Dr. Hilary P. Grocott, Editor-in-Chief, Canadian Journal of Anesthesia.

Author contributions Kokila $N$. Thenuwara and Tatsuya Yoshimura helped design and conduct the study. Yoshinori Nakata helped design the study. Franklin Dexter helped design and conduct the study, analyze the data, and write the manuscript.

Funding Departmental funding.

\section{References}

1. Sento Y, Suzuki T, Suzuki Y, Scott DA, Sobue K. The past, present and future of the postanesthesia care unit (PACU) in Japan. J Anesth 2017; 31: 601-7.

2. American Society of PeriAnesthesia Nurses. Frequently Asked Questions. Available from URL: http://www.aspan.org/ClinicalPractice/FAQs (accessed June 2018).

3. O'Neill L, Dexter F, Zhang $N$. The risks to patient privacy from publishing data from clinical anesthesia studies. Anesth Analg 2016; 122: 2017-27.

4. O'Neill L, Dexter F, Park SH, Epstein RH. Uncommon combinations of ICD10-PCS or ICD-9-CM operative procedure codes account for most inpatient surgery at half of Texas hospitals. J Clin Anesth 2017; 41: 65-70.

5. Masursky D, Dexter F, Kwakye MO, Smallman B. Measure to quantify the influence of time from end of surgery to tracheal extubation on operating room workflow. Anesth Analg 2012; 115: 402-6.

6. Dexter F, Epstein RH. Increased mean time from end of surgery to operating room exit in a historical cohort of cases with prolonged time to extubation. Anesth Analg 2013; 117: 1453-9.

7. Divine G, Norton HJ, Hunt R, Dienemann J. Statistical grand rounds: a review of analysis and sample size calculation considerations for Wilcoxon tests. Anesth Analg 2013; 117: 699-710.

8. Epstein RH, Dexter F, Lopez MG, Ehrenfeld JM. Anesthesiologist staffing considerations consequent to the temporal distribution of hypoxemic episodes in the postanesthesia care unit. Anesth Analg 2014; 119: 1322-33.

9. Smallman B, Dexter F, Masursky D, et al. Role of communication systems in coordinating supervising anesthesiologists' activities outside of operating rooms. Anesth Analg 2013; 116: 898-903. 
10. Duncan PG, Shandro J, Bachand R, Ainsworth L. A pilot study of recovery room bypass ("fast-track protocol") in a community hospital. Can J Anesth 2001; 48: 630-6.

11. Apfelbaum JL, Walawander CA, Grasela TH, et al. Eliminating intensive postoperative care in same-day surgery patients using short-acting anesthetics. Anesthesiology 2002; 97: 66-74.

12. Williams BA, Kentor ML, Williams JP, et al. PACU bypass after outpatient knee surgery is associated with fewer unplanned hospital admissions but more phase II nursing interventions. Anesthesiology 2002; 97: 981-8.

13. Dexter F, Macario A, Manberg PJ, Lubarsky DA. Computer simulation to determine how rapid anesthetic recovery protocols to decrease the time for emergence or increase the phase I postanesthesia care unit bypass rate affect staffing of an ambulatory surgery center. Anesth Analg 1999; 88: 1053-63.

14. Dexter F. Economics of Anesthetic Agents. Available from URL: https://www.FranklinDexter.net/Lectures/DrugCosts.pdf (accessed June 2018).

15. Metzler EC, Kodali BS, Urman RD, Flanagan HL, Rego MS, Vacanti JC. Strategies to maintain operating room functionality following the complete loss of the recovery room due to an internal disaster. Am J Disaster Med 2015; 10: 5-12.

16. Dexter F, Tinker JH. Analysis of strategies to decrease postanesthesia care unit costs. Anesthesiology 1995; 82: 94-101.

17. Dexter F, Epstein RH, Penning DH. Statistical analysis of postanesthesia care unit staffing at a surgical suite with frequent delays in admission from the operating room - a case study. Anesth Analg 2001; 92: 947-9.

18. Epstein RH, Dexter F, Traub RD. Statistical power analysis to estimate how many months of data are required to identify PACU staffing to minimize delays in admission from ORs. J Perianesth Nurs 2002; 17: 84-8.
19. Dexter F, Epstein RH, Marcon E, de Matta R. Strategies to reduce delays in admission into a postanesthesia care unit from operating rooms. J Perianesth Nurs 2005; 20: 92-102.

20. Dexter F, Wachtel RE, Epstein RH. Impact of average patient acuity on staffing of the phase I PACU. J Perianesth Nurs 2006; 21: 303-10

21. Ehrenfeld JM, Dexter F, Rothman BS, et al. Lack of utility of a decision support system to mitigate delays in admission from the operating room to the postanesthesia care unit. Anesth Analg 2013; 117: 1444-52.

22. Khorasanian D, Dexter F, Moslehi G. Analyses of the phase I postanesthesia care unit baseline capacity and effect of disruptions to its beds or nurse availability on operating room workflow. Int J Plan Sched 2018 (in press).

23. Aldrete JA. The post-anesthesia recovery score revisited. J Clin Anesth 1995; 7: 89-91.

24. Tessler MJ, Mitmaker L, Wahba RM, Covert CR. Patient flow in the post anesthesia care unit: an observational study. Can J Anesth 1999; 46: 348-51.

25. Brown I, Jellish WS, Kleinman B, et al. Use of postanesthesia discharge criteria to reduce discharge delays for inpatients in the postanesthesia care unit. J Clin Anesth 2008; 20: 175-9.

26. Marcon E, Dexter $F$. Impact of surgical sequencing on post anesthesia care unit staffing. Health Care Manag Sci 2006; 9: 8798.

27. Marcon E, Dexter F. An observational study of surgeons' sequencing of cases and its impact on postanesthesia care unit and holding area staffing requirements at hospitals. Anesth Analg 2007; 105: 119-26. 